\title{
Daily spiritual experiences among medical students of North India
}

\author{
Bhola Nath $^{1}$, Shiv Kumar Yadav ${ }^{2 *}$ \\ ${ }^{\mathbf{1}}$ Professor and Head, ${ }^{\mathbf{2}}$ Assistant Professor, ${ }^{\mathbf{1}, \mathbf{2}}$ Dept. of Community Medicine, Govt. Doon Medical College, Dehradun, \\ Uttarakhand, India
}

*Corresponding Author:

Email: drskynet85@gmail.com

\begin{abstract}
Introduction: Spiritual health is an essential component which contributes towards overall wellbeing of an individual. Spiritual healthy people tend to bear stress of life more comfortably as compared to others. It is well documented in many studies that medical student's faces lots of stress on daily basis as they have to work hard in studies during their long study period to score good marks and progress further. This study was undertaken to quantify the daily spiritual experience among medical student.

Objective: To measure the daily spiritual experience among medical students.

Methods: Cross Sectional Study carried among first year medical students studying in government medical college of north India. Their daily spiritual experiences were measured using standard Daily Spiritual Experiences Scale (DSES). Date analysis was done to measure daily spiritual experiences among medical students.

Results: Among 91 Medical students who participated in the study, 52 (57.1\%) were female and 39 (42.9\%) were male. Majority of participants 84 (92.3\%) were from age group 17-20 years. The response obtained from participants were analysed and range of response was calculated. Daily spiritual experiences was divided into high (19-41), medium (42-54) and low (55-81) as per the tertiles distribution of the data. Among study participants 41(45\%) were found to have higher spiritual experiences, 28(30.8) were having medium, 22(24.2\%) were having low spiritual experiences.

Conclusion: This study has clearly shown that variations exist in experiences of spirituality on daily among medical students. There is a need to improve this spiritual orientation which will help them to bear stress associated with day to day life.
\end{abstract}

Keywords: Daily spiritual experiences, Medical students, DSES.

\section{Introduction}

Health is defined as state of complete physical, mental and social well-being and not merely absence of diseases or infirmity. ${ }^{1}$ The definition itself emphasizes the effects of mental and social component on overall health of an individual, which cannot be neglected and both these component can be very well addressed by spirituality. A spiritual person is peace loving, cooperative, caring for others, believes in goodness and truth and have qualities of forgiveness imbibed in him. ${ }^{2}$ Spirituality emphasis on experiences of a personal relationship with God or a higher power, and feelings of love, gratitude and mercy towards all creatures. ${ }^{3,4}$ Scholars believe that the importance of spirituality in life is not correctly understood by people. Numerous studies have shown that prayer, meditation and selfconsciousness have beneficial effects on psychological health as well as physiological processes such as blood pressure and immune functions of an individual. ${ }^{5-7}$ Various randomized trials have been conducted to know the effects of meditation on physiological function, ${ }^{8}$ which showed that it leads to a reduction in anxiety and depression; and increases life satisfaction and psychological well-being as well as strengthening of immune system. Integrating work with spirituality can greatly enhance personal well-being and creativity of workers as well as will promotes harmony and continuous improvement within organizations which will leads to further progress. ${ }^{9,10}$ Spiritual orientation helps in developing better problem solving and negotiation skills and improves decision-making at the corporate level. ${ }^{11,12}$ Studies have documented that spiritual individual experiences lesser depressive symptoms in daily stressful life events. ${ }^{13,14}$ Few Studies have also shown that older adults with high religious/spiritual beliefs recover faster from depression and anxiety as compared to traditional therapies. ${ }^{15,16}$

Spirituality can be measured by Daily Spiritual Experience scale (DSES) originally developed by Underwood and Teresi ${ }^{17}$ it is a 16 item scale designed to capture how spirituality is experienced in everyday life. ${ }^{18}$ DSES measures the breadth and depth of spiritual experience and their relationship with knowledge of the divine and assess the emotional and subjective experiences. The experiences specifically assessed by DSES are feelings and sensations, rather than the cognitive awareness of the beliefs of the individual. ${ }^{18}$ DSES measure one's personal spiritual experiences, rather than received beliefs or specific behaviour's (which can be copied from others) and which makes this scale non religion-Specific. ${ }^{17}$ Lower daily spirituality score on the DSES reflects presence of psychosocial stress, anxiety and depression; while higher indicates with optimism, good social support, and individual's satisfaction with life. ${ }^{17,19-21}$

Medical education has been reported to be one of the most stressful academic curricula worldwide which severely affects the physical and mental health of medical students. The main factors which contributes to development stress among medical students are high parental expectations, peer pressure, examination fear, 
financial problems, relationship disharmony, lack of leisure time, and aspirations for higher studies. ${ }^{22,23}$

This study is conducted to measure the daily spiritual experience among medical students as.

\section{Objectives}

To measure the daily spiritual experience among medical students of north India.

\section{Methodology}

Cross sectional study conducted among MBBS first professional students studying in government medical college of north India. Total 91 MBBS students were enrolled after taking informed consent in this study by purposive sampling method. Each study participant was provided with standard questionnaire as per Daily Spiritual Experience Scale (DSES). ${ }^{17}$ Students were instructed to give response as per their daily experiences of spirituality. This study is a prospective study and all study participants will be followed up for next 4 years to look for change in their daily spiritual experiences. Date entry was done in MS excel and date analysis was done using open Epi software. Frequency of daily Spiritual experience of each item of DSES was plotted on graphs. Mean and $\mathrm{SD}$ was calculated to continuous data and chi-square test and independent $t$ test was applied to look for any significant differences in the daily spiritual experiences. DSES score was calculated by adding responses given on Likert scale (1-6) for $1^{\text {st }}-15^{\text {th }}$ items. The $16^{\text {th }}$ item of DSES scale was evaluated separately as assessment for this item was done on 4-point Likert scale. Total DSES scores were further categorized into tertiles based on the distribution of responses [high spiritual experiences (19-41), medium spiritual experiences (42-54), and low spiritual experiences (55-81).

Study tool (DSES): Underwood and Teresi $(2002)^{17}$ and Underwood (2006) ${ }^{18}$ developed Daily Spiritual Experiences Scale (DSES) which consists of 16 items (questions) of which $1^{\text {st }}-15^{\text {th }}$ scoring is done on a Likert 6 -point scale $(1=$ many times a day, $2=$ every day, $3=$ most days, $4=$ some days, $5=$ once in a while, $6=$ never) and the last $16^{\text {th }}$ item (In general, how close do you feel to God?) is assessed on a Likert scale of 1 (Not at all close) to 4 (As close as possible) The scale assess the experiences of spirituality rather than particular religious beliefs or behaviour's and provides an assessment of religiousness/spirituality in terms as expressed in daily life. A higher total score indicates a lower level of daily spiritual experience. ${ }^{18}$

\section{Result}

Socio-demographic Profile of Study Participants: The study involved 91 MBBS first professional students among them $52(57.1 \%)$ were female and 39 (42.9\%) were male. Majority of participants 84 (92.3\%) were from age group 17-20 years and rest were above 20 years. among them majority $80(87.9 \%)$ was residing in hostel as compared to their own home 11(12.1\%).While 54(59.3\%) were from urban background rest were belonging to rural background $37(40.7 \%)$. Among participants majority 84 (92.3\%), were from Hindu religion followed by $5(5.5 \%)$ from Islam Relgion, 1 (1.1\%) from Sikh and 1 (1.1\%) Jain as shown in table 1 .

Education status of parents also plays an important role in religious and spiritual orientation of the child. Taking this into consideration education status of mother and father of students was also assessed. During assessment it was found that among mothers 24(26.4\%) were postgraduate, $35(38.5 \%)$ were graduate, $11(12.1 \%)$ studied up to senior secondary, 11(12.1\%) studied up to secondary, $3(3.3 \%)$ up to middle, $2(2.1 \%)$ up to primary and $5(5.5 \%)$ mothers were illiterate respectively. While assessing the education status of father, it was found that $32(35.2 \%)$ were post graduate, $38(41.8 \%)$ were graduate, $11(12.1 \%)$ studied up to senior secondary, $7(7.7 \%)$ studied up to secondary, $2(2.1 \%)$ up to middle, $1(1.1 \%)$ up to primary education level as shown in table 1.

Table 1: Profile of the study participants $(n=91)$

\begin{tabular}{|c|c|c|}
\hline \multicolumn{2}{|c|}{ Variable } & Frequency \\
\hline \multirow[t]{2}{*}{ Gender } & Male & 39 \\
\hline & Female & 52 \\
\hline \multirow[t]{3}{*}{ Age Group } & $17-18$ years & 42 \\
\hline & 19-20 years & 42 \\
\hline & $>20$ years & 7 \\
\hline \multirow[t]{2}{*}{ Residence } & Hosteller & 80 \\
\hline & Day Scholar & 11 \\
\hline \multirow[t]{2}{*}{ Background } & Rural & 37 \\
\hline & Urban & 54 \\
\hline \multirow{7}{*}{$\begin{array}{c}\text { Mother } \\
\text { Education }\end{array}$} & Illiterate & 5 \\
\hline & Primary & 2 \\
\hline & Middle & 3 \\
\hline & Secondary & 11 \\
\hline & Senior Secondary & 11 \\
\hline & Graduate & 35 \\
\hline & Post Graduate & 24 \\
\hline \multirow{6}{*}{$\begin{array}{c}\text { Father } \\
\text { Education }\end{array}$} & Primary & 1 \\
\hline & Middle & 2 \\
\hline & Secondary & 7 \\
\hline & Senior Secondary & 11 \\
\hline & Graduate & 38 \\
\hline & Post Graduate & 32 \\
\hline \multirow[t]{4}{*}{ Religion } & Hindu & 84 \\
\hline & Muslim & 5 \\
\hline & Jain & 1 \\
\hline & Sikh & 1 \\
\hline
\end{tabular}

Spiritual Experiences among Medical Students: Daily spiritual experiences of study participants was obtained by using DSES which measure the experiences of spirituality on 16 item(questions) and scoring is done on 6 point Likert scale for item 1-15 and scoring is done on 4 point Likert scale for item number 16 as mentioned in methodology section. Daily 
spiritual experiences of participants are extrapolated in graph 1 (item 1-15) and graph 2 (item 16).

The response obtained from participants were analysed and range of response was calculated and spiritual experience was divided as per the tertiles distribution of the data into high (19-41), medium (4254) and low (55-81). Among study participants $41(45 \%)$ were found to have higher spiritual experiences, $28(30.8 \%)$ were having medium and 22(24.2\%) were having low spiritual experiences. The gender wise distribution showed $22(42.3 \%)$ female and 19(48.7\%) male were having higher daily spiritual experiences followed by $19(36.5 \%)$ females and $9(23.1 \%)$ males were having medium spiritual experiences and rest 11(21.2\%) females and 11(28.2\%) males were having low daily spiritual experiences. there was no significant difference in spiritual experience based on gender as p value was found to be 0.37 .

Detailed assessment of daily spiritual experiences among medical students as extrapolated in graph 1 shows that presence of God is experienced by 24 students every day, while 3 students' responded they never experienced it. When assessed about connection throughout life with God, 29 students expressed that they experience it daily. Regarding source of strength from religion 32 students experience strength every day from their religion while 7 students expressed that they never experienced it. Guidance of God in daily activities is experienced by 26 students many times a day while 24 students experiences it at least once daily that there is GOD who guides them in daily activities. Gratitude was expressed in form of being thankful to God for blessing by 36 students on daily basis while selfless caring for other was experienced by 35 students on most of the days. When it comes to forgiveness 36 students expressed that they accept other's wrong behaviour in some days but not on usual basis.one of the remarkable finding was that 12 students have no desire to be in union with God.

Presence of gender wise differences in daily spiritual experience was analysed by calculation mean and Standard deviation of all 15 items of daily spiritual experiences scale but as visible in table 2 . There was no significant difference in spiritual experiences among both group ( $\mathrm{P}$ value $<0.05)$.

Graph 1: Daily spiritual experiences among medical students (n=91)

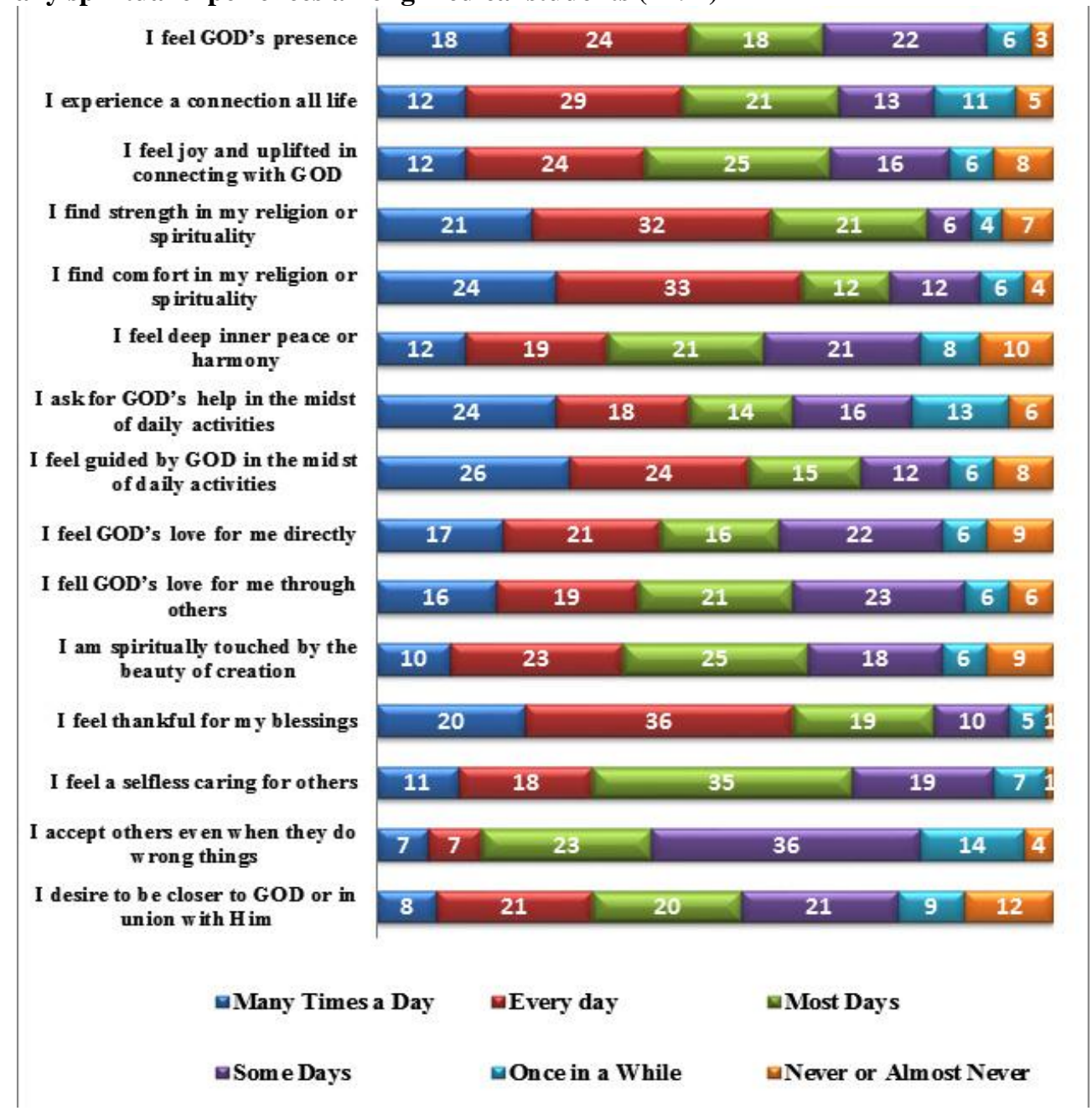


Table 2: Variation in daily spiritual experiences among study participants

\begin{tabular}{|c|c|c|c|c|}
\hline $\begin{array}{l}\text { Item Number } \\
\text { on DSES }\end{array}$ & Variables & $\begin{array}{c}\text { Male } \\
\text { Mean (SD) }\end{array}$ & $\begin{array}{c}\text { Female } \\
\text { Mean } \\
\text { (SD) }\end{array}$ & $\begin{array}{l}\text { Total } \\
\text { Mean } \\
\text { (SD) }\end{array}$ \\
\hline 1 & I feel God's presence & $2.89(1.34)$ & $2.75(1.37)$ & $2.81(1.35)$ \\
\hline 2 & I experience a connection all life & $2.87(1.44)$ & $3.03(1.43)$ & $2.97(1.40)$ \\
\hline 3 & $\begin{array}{l}\text { During worship, or at other times } \\
\text { when connecting with God, I feel } \\
\text { joy, which lifts me out of my daily } \\
\text { concerns }\end{array}$ & $3.05(1.45)$ & $3.03(1.44)$ & $3.04(1.42)$ \\
\hline 4 & $\begin{array}{l}\text { I find strength in my religion or } \\
\text { spirituality }\end{array}$ & $2.54(1.46)$ & $2.59(1.39)$ & $2.57(1.42)$ \\
\hline 5 & $\begin{array}{l}\text { I find comfort in my religion or } \\
\text { spirituality }\end{array}$ & $2.54(1.47)$ & $2.48(1.39)$ & $2.50(1.40)$ \\
\hline 6 & I feel deep inner peace or harmony & $3.07(1.54)$ & $3.40(1.53)$ & $3.26(1.49)$ \\
\hline 7 & $\begin{array}{l}\text { I ask for God's help in the midst } \\
\text { of daily activities }\end{array}$ & $2.92(1.60)$ & $2.94(1.63)$ & $2.93(1.61)$ \\
\hline 8 & $\begin{array}{l}\text { I feel guided by God in the midst } \\
\text { of daily activities }\end{array}$ & $2.51(1.64)$ & $2.83(1.59)$ & $2.69(1.58)$ \\
\hline 9 & I feel God's love for me directly & $3.1(1.54)$ & $3.04(1.59)$ & $3.06(1.54)$ \\
\hline 10 & $\begin{array}{l}\text { I fell God's love for me through } \\
\text { others }\end{array}$ & $2.92(1.44)$ & $3.09(1.45)$ & $3.02(1.42)$ \\
\hline 11 & $\begin{array}{l}\text { I am spiritually touched by the } \\
\text { beauty of creation }\end{array}$ & $2.97(1.33)$ & $3.3(1.44)$ & $3.15(1.42)$ \\
\hline 12 & I feel thankful for my blessings & $2.46(1.14)$ & $2.38(1.17)$ & $2.42(1.17)$ \\
\hline 13 & I feel a selfless caring for others & $2.82(1.17)$ & $3.06(1.14)$ & $2.96(1.14)$ \\
\hline 14 & $\begin{array}{l}\text { I accept others even when they do } \\
\text { things that I think are wrong }\end{array}$ & $3.58(1.12)$ & $3.61(1.19)$ & $3.60(1.19)$ \\
\hline 15 & $\begin{array}{l}\text { I desire to be closer to God or in } \\
\text { union with Him }\end{array}$ & $3.18(1.48)$ & $3.6(1.51)$ & $3.42(1.49)$ \\
\hline \multicolumn{2}{|l|}{ Total Mean (SD) } & $43.46(12.18)$ & $45.2(12.34)$ & $44.46(12.02)$ \\
\hline
\end{tabular}

somewhat close to God, while 4(4.4\%) students do not experience any closeness to God as shown in graph 2 which is item number 16 of DSES scale.*

Assessment of students experiences about how much close they feel to be near to God and it was found that $21(23.1 \%)$ were having experience of being as much close to God as much possible followed by $28(30.8 \%)$ students experiences being very close to God. Almost 38(41.2\%) students still have doubt and feel themselves

Graph 2:-Daily spiritual experience among students (n=91)

How much close you feel to God*?

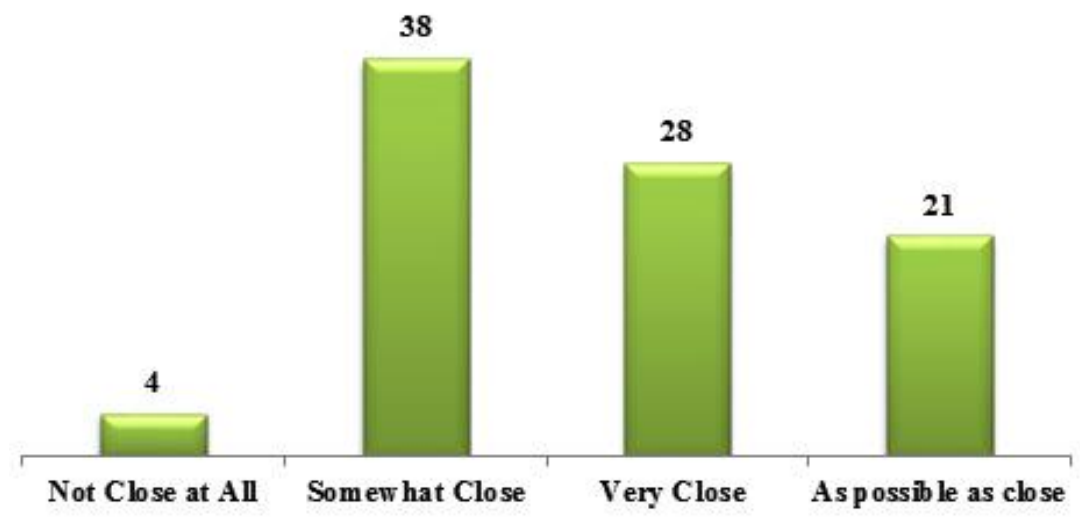




\section{Discussion}

One of the major finding of this study is that daily spiritual experiences varies among participants. Spiritual orientation play a key role in providing positive state of mind and satisfied life. ${ }^{24}$

Among study participants $41(45 \%)$ were found to have higher spiritual experiences, $28(30.8 \%)$ were having medium daily spiritual experiences and 22(24.2\%) were having low spiritual experiences. One of the finding of a previous study was that higher education can often lead to re-examination of fundamental beliefs, and consequent rejection of religious principles and spiritual values, leading to a decrease in daily spiritual experience. ${ }^{20}$ The gender wise distribution showed $22(42.3 \%)$ female and $19(48.7 \%)$ male were having higher spiritual experiences and 19(36.5\%) females and 9(23.1\%) males were having medium spiritual experiences on daily basis and rest 11(21.2\%) females 11(28.2\%) males having low spiritual experiences. There was no significant difference in spiritual experience based on gender as $\mathrm{p}$ value was found to be 0.37 . Presence of gender wise differences in daily spiritual experience for each item of DSES was analysed by calculation mean and Standard deviation of all 15 items of daily spiritual experiences scale but as visible in table 2, there was no significant difference in spiritual experiences among both groups ( $p$ value -0.50). This study tried to investigated the relationship between daily spiritual experience and gender which was found to be nonsignificant one of the reason being small sample size. The role of gender in daily spiritual experience still remains open for future research. Daily spirituality is an experience relatively autonomous and independent of various social parameters at least in the samples presented here. Previous studies conducted in a sample of older adults in the United States showed that there was no significant association of age, education, social class or employment with respect to daily spiritual experiences. $^{14}$

In this study 24 students responded that they experience GOD's presence everyday while 3 responded they never experienced it. When assessed about connection throughout life with GOD, 29 responded they experience it daily. Regarding strength they receive from religion 32 students experience strength everyday while 7 never receive it. Although it is difficult to distinguish religiousness from spirituality, this result strengthens the view that spirituality is a characteristic of the person, and that it is not dependent upon any specific religious creed. Spirituality provides the compassion, flexibility and courage required in the struggle for social change. ${ }^{25,26}$ Gratitude was expressed in form of being thankful to GOD for blessing by 36 students on daily basis while selfless caring for other was experienced by 35 students on most of the days. Many scholars disagree with the suggestion that spirituality is a personality factor. A study done by
Zinnbauer et $\mathrm{al}^{27}$ was the first to quantitatively study differences between religiousness and spirituality. When it comes to Forgiveness 36 students expressed that they accept other's wrong behaviour in some days but not on usual basis.one of the remarkable finding was that 12 students have no desire to be in union with GOD. There is need to find these natural cognitive dispositions that promote religiousness/spirituality. Perhaps, to understand spirituality as a universal phenomenon, we must look beyond the personality and give importance to several complex cognitive processes like behaviours, religious thoughts, political systems, family relations or ethnic coalitions. ${ }^{28}$

\section{Conclusion}

This study has clearly shown the spiritual orientation and daily spiritual experience exists among medical students. This Spiritual orientation will help them to bear stress associated with day to day life. Few Students still have low spiritual experiences which is a point of concern as medical profession will get more stressful as they will advance in their profession and spiritual orientation will help them to overcome that phase. Students who have lost their sight of the spiritual dimension mainly due to the pressures and hassles of daily life should use their free time to restore and regain spirituality.

Limitation of the Study: First, the study could have benefited from a larger and more heterogeneous sample. The sample size was less $(n=91)$. It would be good to have greater representation than of the religious groups characterizing the general public in order to establish contrasts. The future study could be more fully explored by gathering data from among the full range of religious and spiritual orientations. The results indicate an urgent need to further examine intercultural aspects of spirituality by assessment of cultural differences and its effect on spiritual orientation and other additional measurement scale could also be employed, because Likert scales can be methodologically limiting for studying the crosscultural differences. As it is not clear how daily spiritual experience mediates between religiousness and psychological well-being it would be desirable to use additional instruments assessing psychological wellbeing.

\section{References}

1. World Health Organization. WHO (1978). Health for All, Sr. No.1.

2. Rayburn, C.A. (2004). Religion, spirituality, and health. American Psychologist, 59(1), 52-53.

3. Emmons, R.A., \& McCullough, M.E. (2003). Counting blessings versus burdens: An experimental investigation of gratitude and subjective well-being in daily life. Journal of Personality and Social Psychology, 84(2), 377-389. 
4. Underwood, L.G. (2005). Interviews with Trappist Monks as a contribution to research methodology in the investigation of compassionate love. Journal for the Theory of Social Behaviour, 35(3), 285-302.

5. Hostetler, J. (2002). Humor, spirituality, and well-being. Perspectives on Science and Christian Faith, 54(2), 108113.

6. Meyerstein, I., \& Ruskin, G. (2007). Spiritual tools for enhancing the pastoral visit to hospitalized patients. Journal of Religion and Health, 46(1), 109-122.

7. Underwood, L.G. (1999). A working model of health: Spirituality and religiousness as resources: Applications to persons with disability. Journal of Religion, Disability \& Health, 3(3), 51-71.

8. Davidson, R.J. (2004). Well-being and affective style: Neural substrates and biobehavioural correlates. Philosophical Transactions of the Royal Society of London, 359, 1395-1411.

9. Butts, D. (1999). Spirituality at work: An overview. Journal of Organizational Change Management, 12(4), 328-331.

10. Marques, J.F. (2004). Spirituality in the workplace: Establishing a broadly acceptable definition of this phenomenon. Unpublished doctoral dissertation, Pepperdine University, California.

11. Shakun, M.F. (2006). Spiritual rationality: Integrating faith-based and secular-based problem solving and negotiation as systems design for right action. Group Decision and Negotiation, 15, 1-19.

12. Fernando, M., \& Jackson, B. (2006). The influence of religion-based workplace spirituality on business leaders decision-making: An inter-faith study. Journal of Management \& Organization, 12(1), 23-39.

13. Kendler, K.S., Liu, X.Q., Gardner, C.O., McCullough, M.E., Larson, D., \& Prescott, C.A. (2003). Dimensions of religiosity and their relationship to lifetime psychiatric and substance use disorders. The American Journal of Psychiatry, 160(3), 496-503.

14. McCauley, J., Tarpley, M.J., Haaz, S., \& Bartlett, S.J. (2008). Daily spiritual experiences of older adults with and without arthritis and the relationship to health outcomes. Arthritis \& Rheumatism (Arthritis Care \& Research), 59(1), 122-128.

15. Hawkins, R.S., Tan, S.Y., \& Turk, A.A. (1999). Secular versus Christian inpatient cognitive-behavioral therapy programs: Impact on depression and spiritual well-being. Journal of Psychology and Theology, 27, 309-331.

16. Koenig, H.G., Cohen, H.J., Blazer, D.G., Pieper, C., Meador, K.G., Shelp, F., Goli, V., \& DiPasquale, B. (1992). Religious coping and depression among elderly, hospitalized medically ill men. The American Journal of Psychiatry, 149, 1693-1700.

17. Underwood, L.G., \& Teresi, J.A. (2002). The Daily Spiritual Experience Scale: Development, theoretical description, reliability, exploratory factor analysis, and preliminary construct validity using health-related data. Annals of Behavioral Medicine, 24(1), 22-33.

18. Underwood, L.G. (2006). Ordinary spiritual experience: Qualitative research, interpretive guidelines, and population distribution for the Daily Spiritual Experience Scale. Archive for the Psychology of Religion/Archiv für Religions psychologie, 28(1), 181-218.

19. Ellison, C.G., \& Fan, D. (2008). Daily spiritual experiences and psychological well-being among US adults. Social Indicators Research, 88(2), 247-271.

20. Kalkstein, S. (2006). The Daily Spiritual Experiences Scale and psychological and physical well-being: Demographic comparisons, scale validation, and outcome measures. Unpublished doctoral dissertation, Columbia University in the City of New York.

21. Mayoral, E., Underwood, L.G., Laca, F., \& Mejía, J.C. (in press). Validation of the Spanish version of Underwood's Daily Spiritual Experience Scale in Mexico. International Journal of Hispanic Psychology.

22. Abraham RR, Zulkifli EM, Fan ES, Xin GN, Lin JI. A report on stress among first year students in an Indian medical school. South East Asian J Med Educ 2009;3:78-81.

23. Gupta S, Ray TG, Saha I. Overweight, Obesity and influence of stress on body weight among Undergraduate students. Indian J Community Med 2009;34:255-7.

24. Hills, P., Francis, L.J., Argyle, M., \& Jackson, C.J. (2004). Primary personality trait correlates of religious practice and orientation. Personality and Individual Differences, 36, 61-73.

25. Jiliberto, R. (2004). Espiritualidad, sociedad y sostenibilidad. Polis, Revista de la Universidad Bolivariana, 3(8).

26. Razeto, L. (2004). Espiritualidad y acción social: Entre el verticalismo y el horizontalismo. Polis, Revista de.

27. Zinnbauer, B.J., Pargament, K.I., Cole, B., Rye, M.S., Butter, E.M., Belavich, T.G., Hipp, K.M., Scott, A.B., \& Kadar, J.L. (1997). Religion and spirituality: Unfuzzying the fuzzy. Journal for the Scientific Study of Religion, 36(4), 549-564.

28. Boyer, P. (2008). Religion: Bound to believe? Nature, $455,1038-1039$. 